\title{
Structural Design and Experimental Analysis on Key Structure of Sand Barrier Burying Machine
}

\author{
Zheng Weiqiang ${ }^{1,2}$, Zhang Liping ${ }^{1, *}$, Zhou Jianping $^{1}$ and Ge Yuanyue ${ }^{3}$
}

\author{
${ }^{1}$ College of Mechanical Engineering, Xinjiang University, Urumchi 830046, China \\ ${ }^{2}$ State Key Laboratory for Manufacturing Systems Engineering, Xi'an Jiaotong University, Xi'an, 710054, China \\ ${ }^{3}$ Faculty of Science and Techonogy, Norwegian University of Life Sciences, Aas, 1432, Norway
}

Received 12 March 2021; Accepted 3 June 2021

\begin{abstract}
Sand-barrier burying is an important approach to decrease desertification. The existing sand-barrier burying machine completes the sand-barrier burying by pressed mode, thereby resulting in great burying resistance. Although sand-barrier burying based on ditching decreases the burying resistance, the sand-barrier burying quality is influenced given that sand particles with great mobility easily fill in the ditches. A burying mechanism integrating ditching, sand holding, and sand covering was proposed to decrease resistance against sand-barrier burying, prevent filling in of sand particles in ditches, and assure sand-barrier burying quality. Moreover, the structure and performance of the mechanism were discussed. A finite element model of burying integrated mechanism was built using the finite element analysis, and intensities of key components of the mechanism were analyzed. A practical working condition model of burying integrated mechanism was built through numerical simulation of its operation process. The ditching, sand holding, and sand covering performance of the burying integrated mechanism were analyzed. Moreover, the burying performance of the burying integrated mechanism was verified by a field test. Results show that when the burying integrated mechanism operates stably, the regions with great stress occur in the middle of the cutting blade of the ditching part and the joint between the sand holding plate and sand covering plate, with stresses of 107.7 and $395 \mathrm{MPa}$, respectively, within the stress permissible range of materials. According to simulation and field test, the burying depth and height of the burying integrated mechanism satisfy the burying requirements. The burying resistance decreases, and the sand particles do not backfill after ditching, resulting in good burying effect. The proposed conclusion provides references for the development of wind prevention and sand fixation machines and facilitates the mechanization process of sand-barrier burying.
\end{abstract}

Keywords: Mechanical sand barrier; Burying integrated mechanism; Burying mechanism; Wind prevention and sand fixation

\section{Introduction}

At present, desert and desertification are the most serious environmental problems in the world. Many countries face the hazards of desertification. China is one of the countries with the most extensive desert area and the most desertification hazards in the world $[1,2]$. The desert area in Xinjiang is $430400 \mathrm{~km}^{2}$, accounting for approximately $60 \%$ of the total desert area in China. Xinjiang Province has the most serious desert hazard in China with the most serious desertification hazards in the world. Preventing continuous expansion of desertification is one of the most important environmental and social economic problems of Xinjiang and even China at present $[3,4]$. Improving the condition of human beings and realizing sustainable development of social economy are important. Sand barrier is important to prevent continuous desertification [5]. However, desertification control involves a large range, which requires considerable manpower, materials, and financial resources [1]. Desertification control may not provide benefits in the short run, and sand-barrier burying mainly depends on manpower, resulting in the low burying efficiency, adverse working environment, and high labor intensity of burying.

*E-mail address: lyzzyjs2010@163.com

ISSN: 1791-2377 @ 2021 School of Science, IHU. All rights reserved.

doi:10.25103/jestr.143.24
Thus far, sand-barrier burying machines are few. Existing sand-barrier burying machines have poor adaptation to burying materials and desert terrains and decelerate the process of desertification control by sand barriers.

On this basis, the academic circle has carried out considerable studies on sand prevention mechanism of sand barriers. These studies mainly focus on sand particle movement mechanism based on fluid mechanical theory and particle kinetic theory as well as sand prevention effect of sand barriers thru wind tunnel test and field test. With respect to studies on sand particle movement mechanism based on fluid mechanical theory and particle kinetic theory, the natural movement and movement process of sand particles after encountering the sand barriers are simulated using theoretical calculation and fluent to analyze the dynamics and kinetics of sand particles and disclose the movement mechanism of sand particles. The findings provide scientific references to scientific sand holding [6-8]. Methods, such as wind tunnel test and field test, mainly focus on the sand holding performance of sand barriers by using different materials, different shapes, and different burying methods [9-11]. However, studies on the sandbarrier burying machine are few, and sand barrier is buried 
by pressing mode. It is applicable to flat sand lands, and the burying resistance is exceptional, thereby resulting in the failure of large-scaled promotion. Hence, decreasing the burying resistance and improving the burying performance of sand-barrier burying machines in accordance with the characteristics of sand particles are important to the development of sand-barrier burying equipment.

\section{State of the art}

At present, academic studies on sand-barrier burying machines are few, mainly focusing on the performance of key components of press-in burying equipment. The mature burying machines are few. Ibrahim et al. [12] added the assisting caterpillar-toothed plate on the traditional gear teeth to prevent caught of gear of vehicles into sand dunes during slope climbing. The angle of the assisting caterpillartoothed plate was adjustable in accordance with the slope. When the angle was within $0^{\circ}-30^{\circ}$, the equipment of the assisting caterpillar-toothed plate can decrease the sinking and power consumption of the gear. Irani et al. [13] built a dynamic soil mechanical model applicable to the loose sand soils, in which two dimensionless coefficients related to soil properties, slippage conditions, and vehicle loads were added. Yamamoto et al. [14] discussed the interaction force between the single lug and sand soils through a bench test under different parameters, including angular velocity of single lug, sinking length, and cumulative soil deformation. Moreover, they discussed the movement mechanism on any plane of sand land. Gareth et al. [15] proposed an improved pressure settlement model, which was verified under three terrains including sand land. This model could be used to predict and speculate the maneuvering characteristics of small vehicles under variable terrains. Zhang [16] designed a sand-barrier burying machine with wheat grass band, which was applicable to large-scaled flat sand-barrier burying in desert under small angles $\left(<15^{\circ}\right)$. Wu [17] designed a sand land governing machine that performed pull-type sandbarrier burying and hole sowing of grass seeds at the same time. It increased the use of the machine and adaption of burying materials, but it still could not adapt to sand-barrier burying in complicated terrains. Liu et al. [18, 19] carried out general design, dynamic analysis, multibody dynamic simulation, and test of square sand grass pavement robot for wind prevention and sand fixation as well as design and research of transverse pavement system of stereoscopic sand fixation vehicles. Lu et al. [20, 21] studied the control system and traffic ability of wind prevention and sand fixation robot. The self-propelled straw sand-barrier burying machine was designed by Li and Zheng et al. [22] was characterized full-time all-wheel driving, full-terrain simulation of trafficability characteristics, high bearing capacity and pulling force, and strong ground adaptation. $\mathrm{Li}$ et al. [23] designed a sand-barrier insertion test device to realize sand-barrier burying in sand land. Tang et al. [24, 25] improved the design of straw board of the push-off mechanism by using the principle of inertia force balance and simulated the movement of transverse slotting tool with ADAMS software, thereby obtaining the displacement, velocity, and acceleration curves of the mechanism. These findings laid the foundation for dynamic analysis. Zhang et al. [26] carried out an experimental study on vertical grass insertion of the grass cutterhead of the square sand-barrier paving device. Xian et al. [27] studied the value and influencing factors of insertion resistance and traction force during grass sand-barrier pavement, which provided theoretical parameters for the design of the pavement system and traction dynamic design of the sand fixation device. Yi [28] discussed the spraying mechanism of sand fixation vehicles through the Computational Fluid Dynamics model and disclosed the spraying laws of sand fixation. This finding provided theoretical and technological guidance for research and development of sand fixation vehicles. Subsequently, scholars further studied and tested sandbarrier burying machine on this basis and designed the grass square sand-barrier burying machine, resulting in the high burying efficiency. However, they proposed a high requirement on terrain of desert for barrier burying, with great burying resistance and relatively limited adaption.

These studies applied press-in burying mode and focused on the structural design of key components, such as the overall scheme design of the burying machine, strawboard, and cutterhead, as well as kinematics and kinetic analysis. However, studies on the key components of ditching burying mode are rare. A burying integrated mechanism model was constructed based on the design of the key parts of the burying integrated mechanism by using numerical simulation. Finally, the performance of the proposed mechanism was verified through simulation of the burying process, stress analysis of key components, and a practical burying test. Results provide references to study the sandbarrier burying machine.

The rest of this study is organized as follows. Section 3 is design and modeling of the burying integrated mechanism, simulation and analysis of burying process, as well as stress analysis of key components. Section 4 verifies performances of the proposed mechanism, and finally, the conclusions are summarized in Section 5.

\section{Methodology}

\subsection{Structure and working principle of the burying integrated mechanism}

The burying principle of sand barriers includes press-in type and vertical insertion type. The existing sand-barrier burying machines mainly use the press-in mode, which presses the paving sand barriers into sands by the cutter along the middle position. A vertical insertion type was proposed to bury sand barriers, which required processes of ditchingbarrier pavement-sand holding-sand covering. The burying mechanism integrated with ditching, sand holding, and sand covering was determined according to the sand-barrier burying process and the good flow characteristics of sand particles. The burying mechanism integrating ditching, sand holding, and sand covering is the core key component of the insertion-type sand-barrier burying device, and it is mainly composed of the ditching part, sand holding plates, and sand covering part (Fig. 1).

Under the action of traction force in the burying process, sand particles, which are divaricated by the ditching part in front, move backward along the sand holding plate and pile up along the outside of the sand holding plate to assure the width of the ditch. After the sand-barrier materials fall into the ditch, sand particles that arrive at the sand covering plate leak through the sand return hole, thereby completing the sand-barrier burying. The burying quality is determined by structural dimension of ditching, sand holding, and sand covering integrated mechanism given a fixed thickness and burying depth of the sand barriers. Hence, designing and optimizing the ditching, sand holding and sand covering 
integrated mechanism are important to ensure burying quality and burying machine development.

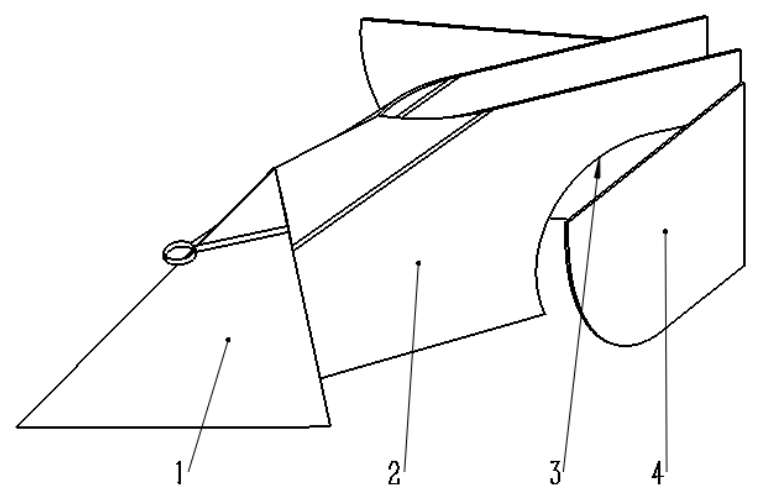

1. Ditching part 2. Sand holding plate 3. Sand returning hole 4. Sand covering part

Fig. 1. Structure of the burying integrated mechanism

\subsection{Key burying structural design}

\subsubsection{Design requirements}

Given the condition of 50 to $80 \mathrm{~mm}$ of ditching width and 150-200 mm of ditching depth, the following requirements should be satisfied:

(1) The burying integrated mechanism has to satisfy the minimum ditching resistance.

(2) Sand particles do not spill over the sand holding plate in the backward moving process.

(3) Sand particles can pass through the sand return hole timely, without piling up.

\subsubsection{Structural design of the burying integrated mechanism}

The mobile core opening share was applied in the ditching part of the burying integrated mechanism according to design requirements, because sand particles have good mobility. This structure has great adjustment range of ditch depth and ditch width. The requirements of sand-barrier burying to ditch can be satisfied by the structural design.

In the normal stable operation of the burying integrated mechanism, the volume of sand particles divaricated by the ditching part is as follows:

$$
Q_{1}=\frac{1}{2} l_{1} l_{2} \rho h \sin \alpha
$$

where $Q_{1}$ is the amount of sand ditching $(\mathrm{kg}) ; \alpha$ is the cutting edge angle of the opening share $\left(^{\circ}\right) ; \quad h$ is the ditching depth $(\mathrm{mm}) ; \rho$ is the density of sand particles $\left(\mathrm{kg} / \mathrm{m}^{3}\right) ; l_{1}, l_{2}$ are length of two sides of opening share $(\mathrm{mm})$.

When the burying integrated mechanism moves in sands at certain traction speed and after sand particles contact with the ditching part, sand particles within a certain range of the contact are disturbed to some extent, and these sand particles move toward the opposite direction with the moving direction at a velocity (Fig. 2). Hence, the divaricated sand volume of the burying integrated mechanism is $Q_{1 \mathrm{t}} \leq Q_{1 p}$. According to several tests, $Q_{1 P}=k Q_{1 t}$, where $\mathrm{k}$ is the disturbing coefficient of sand particles, and $\mathrm{k}=1.1-1.4 . Q_{1 P}$ is the actual amount of sand ditching; $Q_{1 t}$ is the theoretical amount of sand ditching. Hence, we obtain the following:
$Q_{1 p}=\frac{1}{2} k l_{1} l_{2} \rho h \sin \alpha$

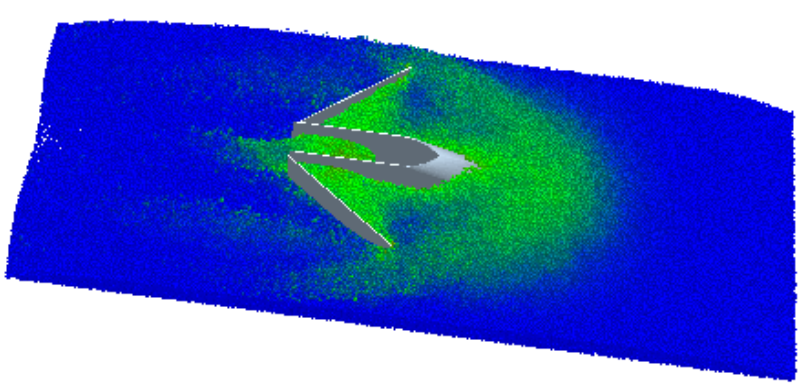

Fig. 2. Disturbances of sand particles of the burying integrated mechanism

A sand holding plate was set in the rear position of the ditching part to ensure the ditching width, prevents sand filling prior to sand-barrier burying, and assures normal sand covering after sand barrier falling in the ditch. The sand holding plate is mainly composed of two parts, namely, the front sand holding plate and the rear sand returning part.

The ditching part entering into sands completely is defined as a period, as follows:

$t=\frac{l_{1} \cos \frac{\alpha}{2}}{v}$

The moving distance along the sand holding plate is obtained as follows:

$s=l_{1} \cos \frac{\alpha}{2}$

Meanwhile, the distance from the inserting depth of sand barriers to the surface for burying shall be considered. Hence, the length of sand holding plate should only satisfy $l_{3} \geq s$.

Sand particles run through the sand holding plate to enter into the sand covering part formed by the sand returning part in the rear position and sand covering plates. Thus, sandbarrier burying is completed through sand return holes at two ends. Sand-barrier burying only has to pile sand particles divaricated by the ditching part at two sides of the sand barrier, but requires no cutting of sand soils. Hence, scraper sand covering plate was selected.

Suppose that sand return hole is unavailable, the sand particle volume between the sand holding plate and sand covering plate is as follows:

$Q_{2 \max }=\frac{1}{2} l_{4} l_{5} \gamma h_{1} \rho \sin \beta$

Where $l_{4}$ is the length of the sand returning part of the sand holding plate $(\mathrm{mm}) . l_{5}$ is the length of the sand covering plate $(\mathrm{mm}) . \gamma$ is the filling coefficient of the sand particles. $\beta$ is the included angle between the scraper sand covering device and sand holding plate $\left(^{\circ}\right) . h_{1}$ is the height of the sand holding plate $(\mathrm{mm})$.

$Q_{3}=q \rho \int_{0}^{l_{4}}\left(a x^{2}-h_{2}\right) d x$ 
where $Q_{3}$ is the volume of sand particles through the sand return hole $(\mathrm{kg}) . \Delta Q$ is the volume of the sand particles that enter into the space between the sand holding plate and sand covering plate in unit time $\left(\Delta \mathrm{Q}=Q_{1}\right)$. a is the length of the sand return hole $\left(\mathrm{a} \leq l_{4}, m m\right) . \mathrm{h}_{2}$ is the height of the sand return hole $(\mathrm{mm})$. $\mathrm{q}$ is the sand particle flow rate of the sand return hole $(\mathrm{m} / \mathrm{s})$.

Sand particles aggregate in the space between sand holding plate and sand covering plate, but they cannot spill over from two plates. It should satisfy the following:

$$
\Delta Q=Q_{3} \leq Q_{2 \max }
$$

To allow the sand particles after ditching to enter into the space between the sand holding plate and sand covering plate completely, $1_{4} \leq l_{5} \cos \beta$ is set. The projection length of the sand covering plate along the moving direction of the burying integrated mechanism is not smaller than the size of the sand return hole along the length direction.

Combining Eqs. (5), (6), and (7) obtains the following:

$$
\mathrm{h}_{2 \max }=\frac{2 \mathrm{a} q l_{4}^{2}-3 l_{4} h_{1} \gamma \tan \beta}{6 q}
$$

Based on these equations, the size and mutual relations of different parts of the burying integrated mechanism can be determined preliminarily, laying foundation for subsequent studies.

\subsubsection{Stress analysis of burying integrated mechanism}

According to the traction balance theory, the ditching depth is constant and the mechanism operates stably when the action co-lines of the resultant force of gravity and resistance force of sand particles and the traction force are in the balanced state. Under normal stable working condition, the burying integrated mechanism mainly bears the traction force, frictional force between sand particles and the burying integrated mechanism, gravity, supporting force, and pressure of sand particles against the ditching part (Fig. 3).

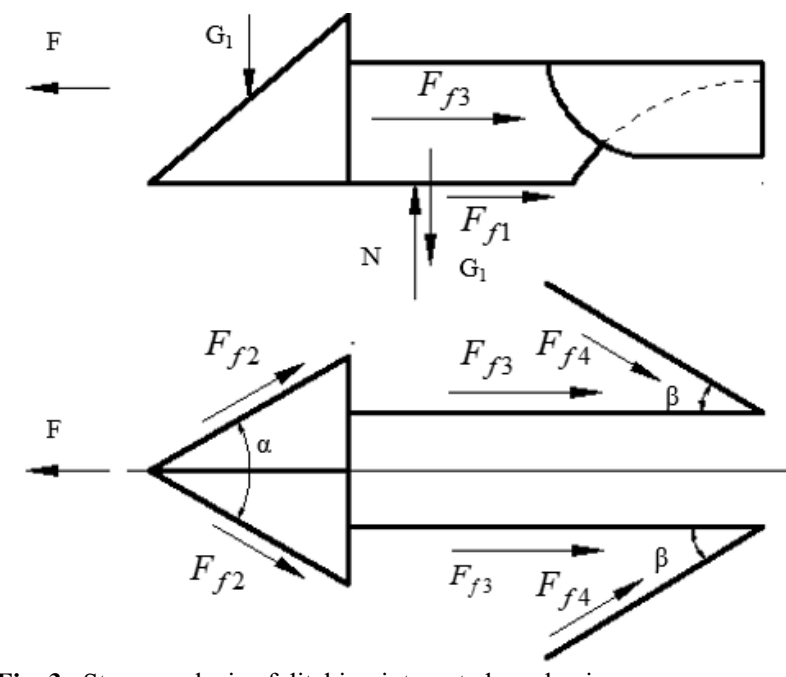

Fig. 3. Stress analysis of ditching integrated mechanism

According to stress analysis of the burying integrated mechanism during stable operation, we obtain the following:

$$
\mathrm{F}=F_{f 1}+2 F_{f 2} \cos \frac{\alpha}{2}+2 F_{f 3}+2 F_{f 4} \cos \beta
$$

$P=\mathrm{F} v$ and $F_{f}=\mu N$ are brought into Eq. (9) to obtain the following:

$$
\mathrm{F}=\mu G_{1}+2 \mu G_{2} \cos \frac{\alpha}{2}+\frac{1}{2} \mu \mathrm{h}_{1}^{2} \operatorname{ctg} \theta l_{3}+\mu l_{4}^{2} h_{1} \rho \sin \beta
$$

where $\mathrm{F}$ is the tractive force $(N) ; \mu$ is the friction coefficient between sand particles and burying integrated mechanism; $\theta$ is the natural angle of repose of sand particles $\left(^{\circ}\right) ; \alpha$ is the cutting edge angle of ditching part $\left(^{\circ}\right) ; \beta$ is the included angle between the scrapper coverage plate and sand holding plate $\left({ }^{\circ}\right) ; l_{4}$ is the length of the sand returning part of the sand holding plate $(\mathrm{mm}) ; \rho$ refers to the sand particle density $\left(\mathrm{kg} / \mathrm{m}^{3}\right)$, and $h_{1}$ denotes the height of the sand holding plate $(\mathrm{mm})$.

The relationship between $\alpha$ and $\beta$ can be calculated according to Eq. (10). Thus, the dimension parameters of different components of the burying integrated mechanism can be determined.

\subsection{Burying process analysis of the integrated mechanism}

\subsubsection{Burying environmental construction}

Burying integrated mechanism and sand land modeling were completed by Solidworks. The models were input into the discrete element software in the. stl format. Parameters were set (Table 1), and the total simulation time was $3.8 \mathrm{~s}$. From 0 $\mathrm{s}$ to $2.8 \mathrm{~s}$, a sand land was generated (Fig. 4), the length, width and height of the sand land are 50, 40, and 30 respectively. The burying integrated mechanism began to move at the speed of $1.6 \mathrm{~m} / \mathrm{s}$ from $2.8 \mathrm{~s}$ (in the mechanical operation process of sand fixation, the moving speed is not

\begin{tabular}{|c|c|c|}
\hline Property & Parameter & Value \\
\hline $\begin{array}{c}\text { Sand } \\
\text { particles }\end{array}$ & $\begin{array}{l}\text { Particle size } d /(\mathrm{mm}) \\
\text { Density } \rho /\left(\mathrm{kg} \mathrm{m}^{-3}\right) \\
\text { Poisson's ratio } v \\
\text { Elasticity modulus } G /(\mathrm{Pa})\end{array}$ & $\begin{array}{l}0.5 \\
1324 \\
0.3 \\
0.7791 \times 10^{8} \\
\end{array}$ \\
\hline $\begin{array}{l}\text { Burying } \\
\text { integrated } \\
\text { mechanism }\end{array}$ & $\begin{array}{l}\text { Density } \rho /\left(\mathrm{kg} \cdot \mathrm{m}^{-3}\right) \\
\text { Poisson's ratio } v \\
\text { Elasticity modulus } G /(\mathrm{Pa})\end{array}$ & $\begin{array}{l}7890 \\
0.269 \\
2.06 \times 10^{11} \\
\end{array}$ \\
\hline Interaction & $\begin{array}{l}\text { Static friction coefficient between } \\
\text { sand particles } \mu_{1} \\
\text { Recovery coefficient between sand } \\
\text { particles } e_{1} \\
\text { Static friction coefficient between } \\
\text { sand particles and burying } \\
\text { mechanism } \mu_{2} \\
\text { Recovery coefficient between sand } \\
\text { particles and burying mechanism } e_{2}\end{array}$ & $\begin{array}{l}0.625 \\
0.01 \\
0.47 \\
0.01\end{array}$ \\
\hline Others & $\begin{array}{ll}\text { Gravitational } & \text { acceleration } \\
g /\left(m / s^{2}\right) & \end{array}$ & 9.8 \\
\hline
\end{tabular}
higher than $3 \mathrm{~km} / \mathrm{h}[1])$. The burying performance was studied.

Table 1. Material characteristic parameters 


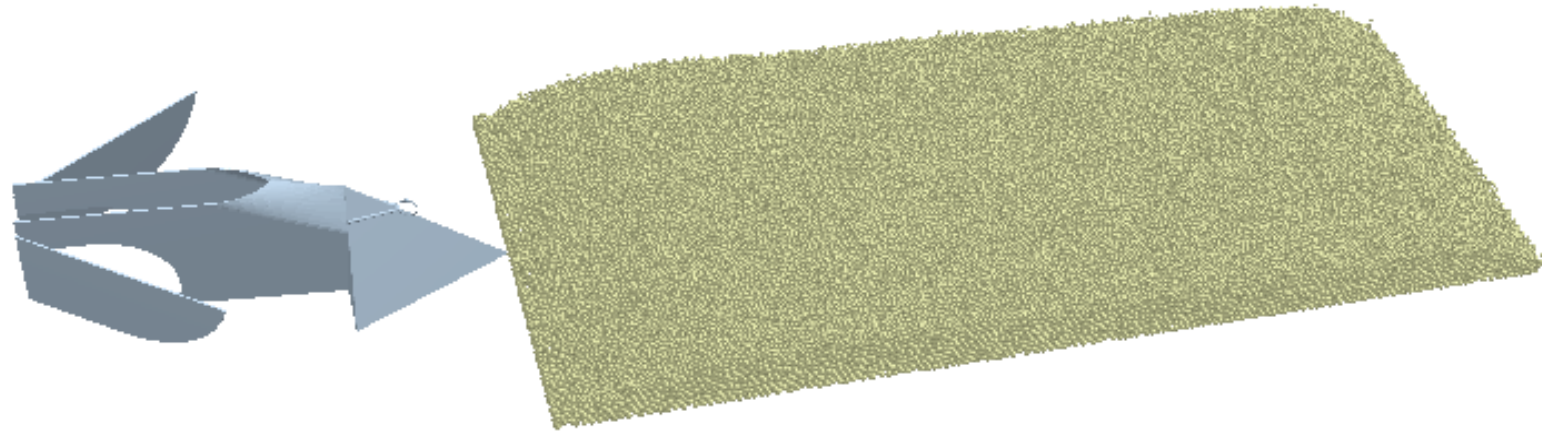

Fig. 4. DEM model in the operation process of the burying integrated mechanism

\subsubsection{Process simulation and result analysis}

The operation process of the burying integrated mechanism was simulated by the particle discrete element method. Interactions between sand particles and the burying integrated mechanism as well as the sand covering after burying were analyzed. Sand particles after operation of the burying integrated mechanism were highlighted by selecting from the Analyst Module in EDEM (Fig. 5). Fig. 5 shows that the burying integrated mechanism advances forward at a certain speed. A sand ditch with a certain width and height was formed in the rear position of the burying integrated mechanism after the sand particles run through the ditching part, sand holding plate, and sand covering part.

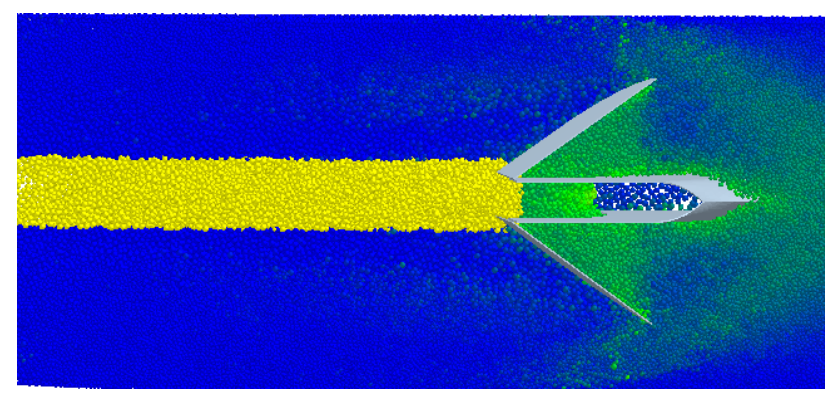

Fig. 5. Simulation process of the burying integrated mechanism

\subsection{Stress analysis of the key structures of the burying integrated mechanism}

The ditching and sand covering components of the burying integrateREd mechanism bear great stresses. Hence, analyzing the stresses on the ditching and sand covering components is necessary. The burying integrated mechanism modeling was completed using Solidworks (Fig. 6). The major materials of the burying integrated mechanism include 45 steel annealed, the modulus of elasticity is $E=2.06 \times 10^{5}$ $\mathrm{MPa}$, the Poisson's ratio is 0.269 , and the thickness is 2.5 $\mathrm{mm}$. The contact surface between the burying integrated mechanism and ground surface is determined as the boundary condition, which is known as constraint. The constraints of the bottom surface are rolling columns or slipping bars. The applied loads are stresses perpendicular to the cutting edge of the opening share, Grid meshing is shown in Fig. 7.

Through modeling, analysis, and calculation of the ditching part, the equivalent stress of the ditching part under the external forces was gained. The equivalent stress isograph of the ditching part under loads is shown in Fig. 8. Evidently, stress concentrations exist on the cutting edge of the ditching part. The maximum stress is $107.7 \mathrm{MPa}$ in the middle of the cutting edge.

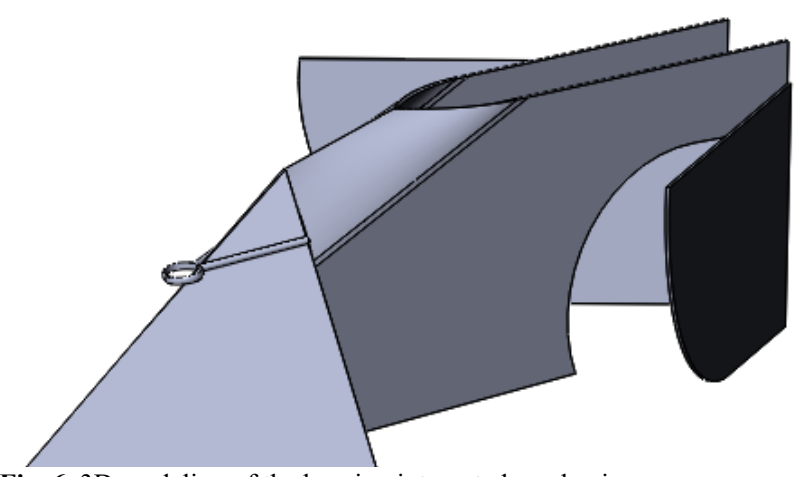

Fig. 6. 3D modeling of the burying integrated mechanism
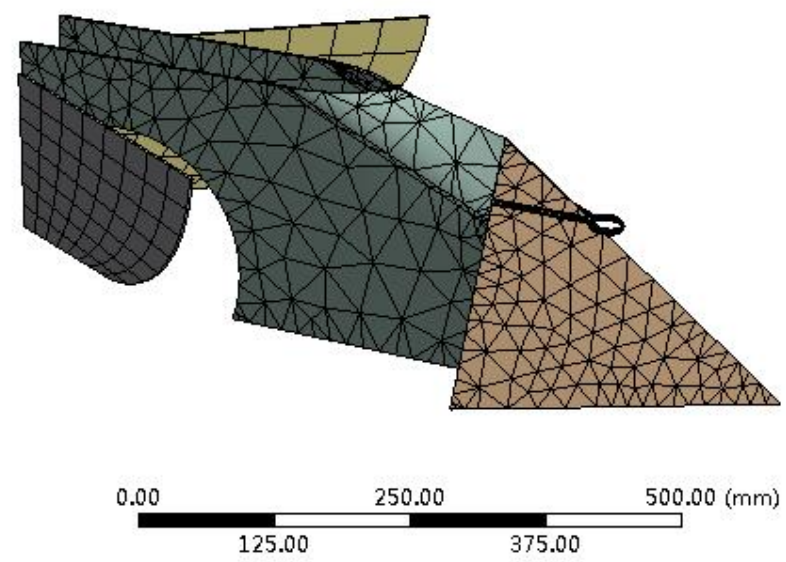

Fig. 7. Grid meshing of burying integrated mechanism

MODAL SOLUTION

VN

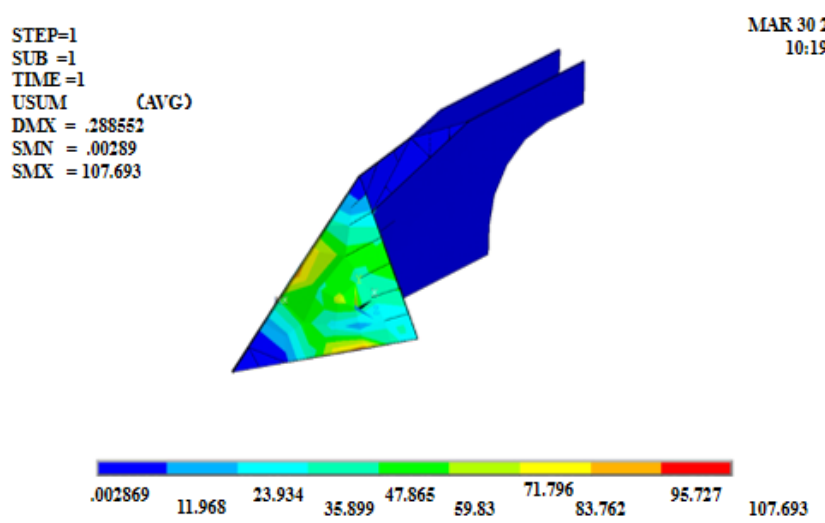

Fig. 8. Equivalent stress isograph of the ditching part

The binding mode between sand holding plate and sand covering plate belongs to welding. Hence, an integral model of the sand covering part was constructed. The equivalent stress of the sand covering part under external loads was gained through analysis and calculation. The equivalent stress isograph of the sand covering part under load is shown in Fig. 9. Evidently, stress concentrations existed at the joint 
between the near end of the scraper of the sand covering part and sand holding plate, and the maximum stress is $395 \mathrm{MPa}$.
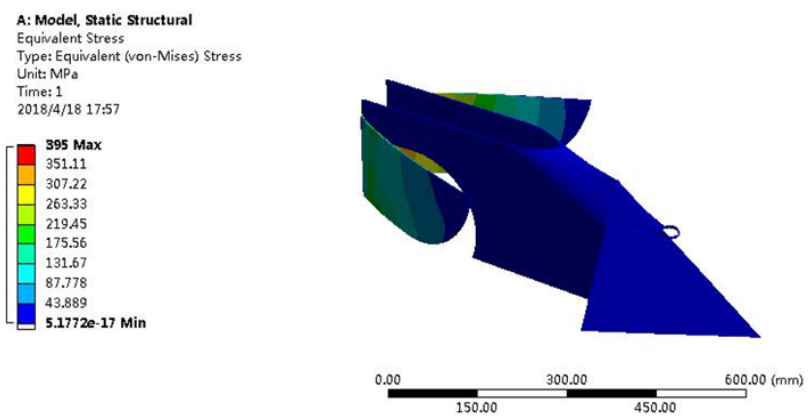

Fig. 9. Equivalent stress isograph of soil coverage device

\section{Result Analysis and Discussion}

\subsection{Study area and materials}

The study area was selected at the edges of the Gurbantunggut Desert (N44057'18.38", E86018'2.21"). In the test, the height of the reed sand barriers was $400 \mathrm{~mm}$, and the reed sand barriers were outcropped for approximately $250 \mathrm{~mm}$. The buried depth was approximately $150 \mathrm{~mm}$, and the thickness was 50-60 $\mathrm{mm}$.

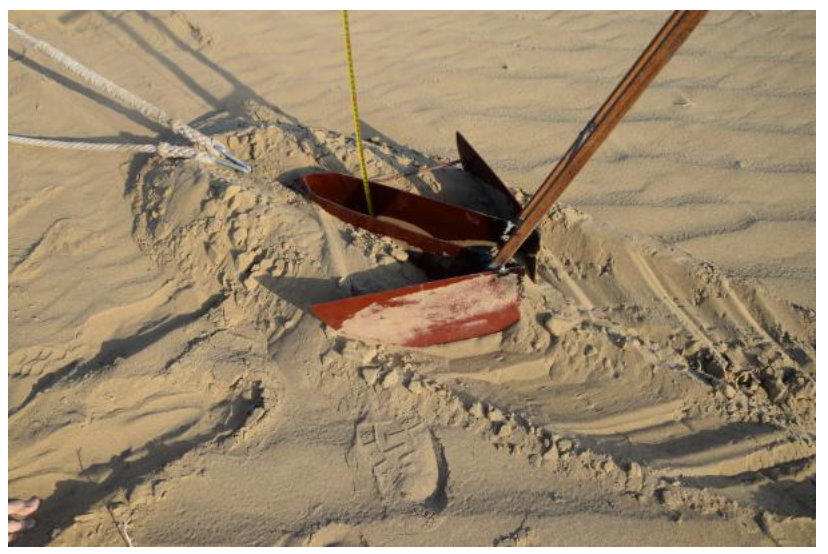

(a) The ditching depth measure

Fig. 10. Ditching sand covering test

\subsubsection{Sand-barrier burying performance test}

On the basis of the test of ditching sand covering performance of the burying integrated mechanism, a sandbarrier burying test was carried out (Fig. 11) to observe whether the burying depth and width satisfy the design standards, whether sand barriers were covered by returned sand timely, and whether coverage hysteresis exists. Results provided references for further optimization of the key structure of the mechanism and follow-up structural design.

In the operation process of the burying integrated mechanism, although sand particles aggregate between the sand holding plate and sand covering plate to some extent, but no spill over along the sand covering plate is observed. Instead, the sand particles complete the coverage of sand barriers along the sand return hole. After completing the sand-barrier burying, the parameters were measured (Fig. 12). The mean thickness $(b)$ of sand barriers was $59 \mathrm{~mm}$, and the mean buried depth $(h)$ was $152 \mathrm{~mm}$, satisfying the design requirements of the burying integrated mechanism.
Experimental devices included the independent burying integrated mechanism of sand barriers and measuring tools.

\subsection{Test process}

\subsubsection{Performance test of ditching sand covering}

The ditching sand covering test was carried out with the burying integrated mechanism given a fixed traction force (Fig. 10). Depth and width of the ditch were measured through the sand holding plate to determine whether they satisfy the design requirements. Meanwhile, the flowing conditions of sand particles, piling of sand particles surrounding the sand return hole, and sand covering performance of the scraper sand covering plate were observed. The burying integrated mechanism moved for 10 $\mathrm{m}$ in the desert given a traction force. The ditching depth of the burying integrated mechanism at sand holding plate was measured several times by the measuring tools. The ditching depth ranged between 140 and $160 \mathrm{~mm}$. Moreover, sand particles ran through the ditching part, sand holding plate, and sand covering plate of the burying integrated mechanism and finally formed a sand ridge, which is $58-62 \mathrm{~mm}$ wide and has some height in the rear position. The practical experiment conforms to the simulation results (Fig. 10).

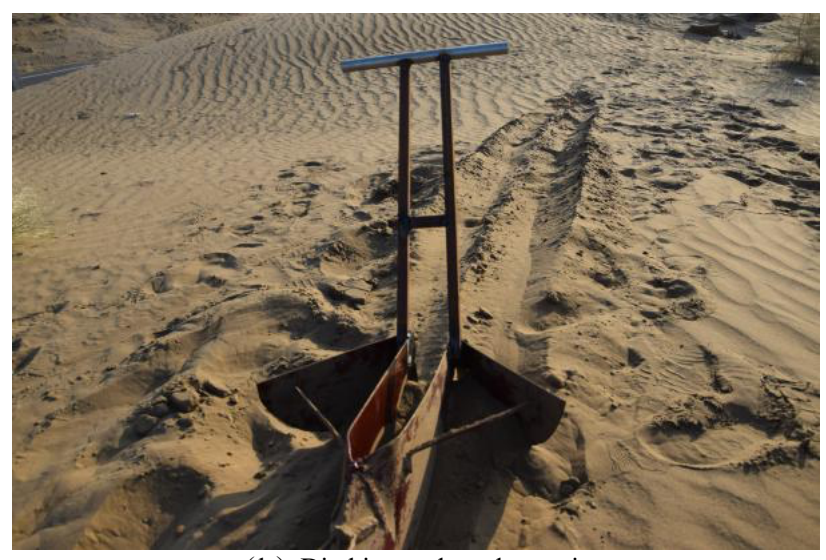

(b) Ditching and sand covering test

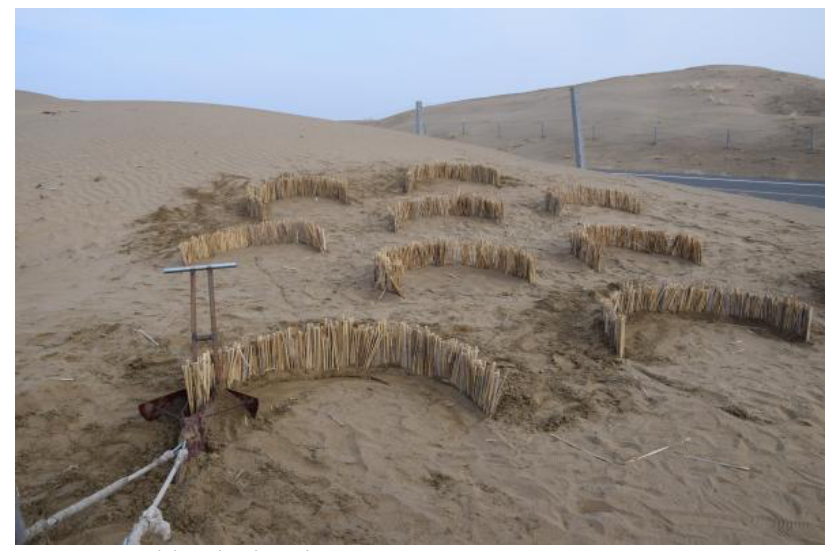

Fig. 11. Sand-barrier burying 


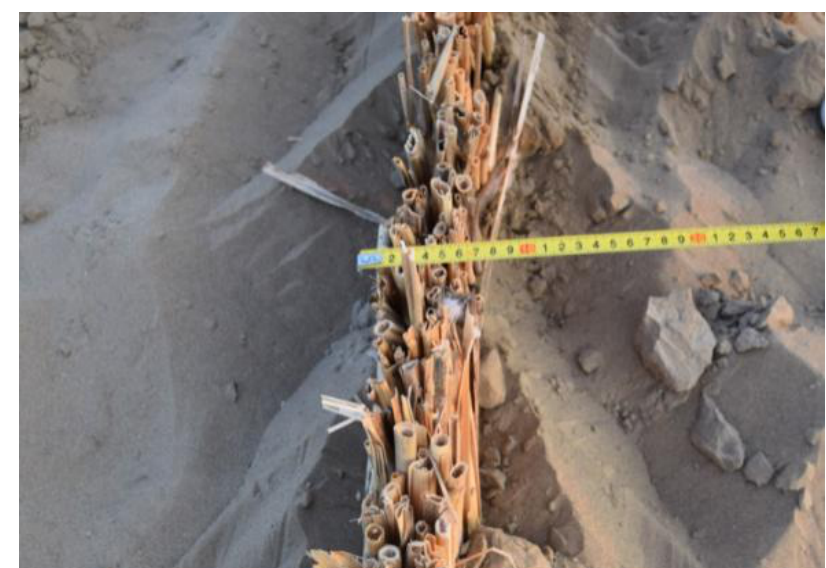

Fig.12. Measurement of sand-barrier burying parameters

\section{Conclusion}

To increase the burying performance of the sand-barrier burying machine and decrease the burying resistance, a ditching burying integrated mechanism was designed and an experimental study was carried out. On the basis of the designs of the ditching part, sand holding plate, and sand covering part of burying integrated mechanism, the operation process simulation and stress analysis of the key components were completed using softwares like Solidworks, EDEM, and Ansys. Moreover, a burying integrated mechanism was manufactured and a field burying performance test was conducted. Some conclusions could be drawn as follows:

(1) Given the fixed buried width and depth, the stress concentration phenomena exist in the middle of the ditching cutting edge and the joint between sand covering part and sand holding plate during stable operation of the burying integrated mechanism. However, the maximum stresses are within the permissible range of the material, satisfying the strength requirements.

(2) During operation of the burying integrated mechanism, no phenomenon that sand particles fill in the ditch in advance is observed. Instead, sand particles complete sand barrier burying under the collaborative effect of returning hole and sand covering plate. The buried depth and width satisfy the design requirements of the burying integrated mechanism and realize the expected goal.

In this study, a sand-barrier burying machine integrated ditching, sand holding, and sand covering is manufactured by combining numerical calculation, simulation, and field test. It has some references to structural optimization of key components of the burying machine. Influences of the burying integrated mechanism structure on the burying performance were discussed, without considering the environmental factors. Future studies focus on the burying performance and continuous improvements of the burying integrated mechanism under comprehensive factors to further increase adaption of the integrated burying mechanism.

\section{Acknowledgments}

The study was supported by Xinjiang Uygur Autonomous Region Natural Science Foundation (No. 2019D01C029), $\mathrm{Xi}$ 'an Jiao tong University State key laboratory for manufacturing systems engineering open Project Research Fund (No. sklms2019012) and Xinjiang University Doctoral Startup Fund (No. XJDXBS2019001).

This is an Open Access article distributed under the terms of the Creative Commons Attribution License.

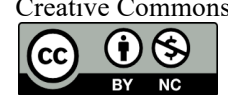

\section{References}

1. Lei, K. 1., Yang, B., Ren, G. T., Fu, C., Yan, P. P., "Structure Design of a Mechanized Sand-Fixation Equipment". Special Purpose Verhicle, 4(05), 2018, pp. 80-83+87.

2. Xu, X.Y., Zhao, P., Tang, J.N., Ji, Y.F., Ma, X.B., "Review on the present status and prospects of research for the machinery in the field of sand-fixing afforestation in China". Forestry and Grassland Machinery, 1(02), 2020, pp. 21-25.

3. Li, H.Y., Ha. s e e d., "Sand-fixing effect and ecological effect of mechanical sand barriers: a review". Journal of Beijing Normal University (Natural Science), 56(01), 2020, pp. 63-67.

4. Bazhenova, O. I., Tyumentseva, E. M., "Soil erosion on the agricultural lands in Southern Siberia: current state, risks, soil protection models". IOP Conference Series: Earth and Environmental Science, 190(1),2018.

5. Ding, X.H., Liu, X.Y., Liu, G. Q., "Research progress and prospects of sand barrier technology in China". Soil and Water Conservation in China, 4(01), 2019, pp. 35-37+69.

6. Keld R. Rasmussen., Michael Sørensen., "Vertical variation of particle speed and flux density in Aeolian saltation. Measurement and modeling". Journal of Geophysical Research: Earth Surface, 113(F02), 2008, pp.1-12.

7. Kang, L.Q., Liu, D.Y., "Numerical investigation of particle velocity distributions in aeolian sand transport". Geomorphology, 115(1), 2009, pp. 156-171.

8. Hu, W.W., Xie. L., Zheng, X. J., "Contract charging of silica glass particles in a single collision". Applied Physics Letters, 101(11), 2012, pp. 3504-615.

9. Sun, H., Liu, J.H., Huang, Q.Q., Zhao, K., "Research on the windproof efficiency of polygonal straw sand barrier". Journal of Beijing Forestry University, 39 (10), 2017, pp. 90-94.
10. Ma, X. xi., Wang, H. F., Li, S. Y., Kang, X. G., Sun, N., "Comparison of Sand-protecting Efficiency and Terrain Adapted of Two Checkerboard Barriers". Bulletin of Soil and Water Conservation, 35(03), 2015, pp. 344-349.

11. Zhang, C.L., Li, Q., Zhou, N., Zhang, J.Q., Kang, L.Q., Shen, Y.P., Jia, W.R., "Field observations of wind profiles and sand fluxes above the windward slope of a sand dune before and after the establishment of semi-buried straw checkerboard barriers". Aeolian Research, 20, 2016, pp. 59-70.

12. Ibrahim, A.N., Aoshima, S., Shiroma, N., Fukuoka, Y., Zhang, D., "The Effect of Assistive Anchor-Like Grousers on Wheeled Rover Performance over Unconsolidated Sandy Dune Inclines". Sensors, 16(9), 2016, pp.1-24.

13. Irani, R. A., Bauer, R. J., Warkentin, A., "A dynamic terramechanic model for small lightweight vehicles with rigid wheel sand grousers operating in sandy soil". Journal of Terramechanics, 48(4), 2011, pp.307-318.

14. Yamamoto, R., Yang, Y., Sun, Y., Ma, S., "Characteristics of lugsoil interaction forces acting on a rotating lug in sandy soil". In: Proceedings of the 2014 IEEE International Conference on Robotic sand Biomimetics (ROBIO), Bali, Indonesia: IEEE, 2014, PP.451456.

15. Gareth, M. Griffith., Matthew, S., "A modified pressure-sinkage model for small, rigid wheels on deformable terrains". Journal of Terramechanics, 48(2), 2011, pp. 149-155.

16. Zhang, M.Z., "7CX-2 Grass Sand Barrier Repairing Machine". Forestry Machinery, (02), 1987, pp. 42-43.

17. Wu, F. m., "2ZB-1.45 Model of Special Planting Barrier Sower", Agriculture Machinery Technology Extension, (07), 2004, pp.40.

18. Shu, Q., Liu j. h., "The overall Design of The Wind-Proof and SandFixing Grass Grid Paving Robot". Transactions of the Chinese Society for Agricultural Machinery, 38(06), 2007, pp. 199-201. 
19. Liu, J. h., Pan, H. b., Shu, Q., "Multi body Dynamic Simulation and Experiments of the Straw-checkerboard Barriers Paving Robot". Transactions of the Chinese Society for Agricultural Machinery, 40(6), 2009, pp. 153-157.

20. Lu, H. m., Guo, X. r., Zhao, Z. g., Li, M. H., Liu, J.H., "Desert trafficability study of trellis grass paving robot". Chinese journal of construction machinery, 4(4), 2006, pp. 389-393.

21. Zhao, Z. g., Lu, H. m., "Experimental Study of Trafficability Robot for Preventing Draughts and Dune Fixation". Journal of Agricultural Mechanization Research, (1), 2008, pp. 189-192.

22. Li, H. t., Zheng, W. q., Liu, P. y., Wei, w. j., Zhang, S. y. "Selfpropelled straw sand barrier burying machine". [EB/OL]. Retrieved from

https://xueshu.baidu.com/usercenter/paper/show?paperid=9b96e $28 \mathrm{~b}$ 7503ea194f659531c49e5d65\&site $=$ xueshu_se, 2016-06-22/2021 $07-16$
23. Li, C., Liu, J. h., Tang, W. g., "Design and Simulation of a Sand Barrier Insertion Test Device”. Agricultural Engineering, 6(05), 2016, pp. 109-112.

24. Tang, W. g., Liu, J. h., Li, C., "Design and Analysis of Transverse Grass Pushing Device with Multi Rod". Agricultural Engineering, 7(02), 2017, pp. 114-117.

25. Tang, w. g., Liu, J. h., Li, c., Yu, Y. z., "Kinematics Research and Simulation of Multicar Transverse Inserted Knife Mechanism". Mechanical Engineering \&Automation, (02), 2017, pp. 38-39.

26. Zhang, H. y., Li, Y. j., Liu, J. h., "Study on Sand Fixing by Simply Pressing Insert Straw". Journal of Agricultural Mechanization Research, 41(12), 2019, pp. 161-167.

27. Xian, A. H., Liu, J. H., Li, C., "Design and Test of Sand Trap for Longitudinal Grass Cutting Mechanism". Journal of Northwest Forestry University, 34(03), 2019, pp. 246-252.

28. Yin, q., "Research on Spraying Mechanism and Experiment of Sand Fixation Vehicle Based on CFD model'. Master thesis of Beijing Forestry University, China, 2020, pp. 20-56. 